\title{
The Effects of Social Media on Public Emergency Response Mechanisms in Sierra Leone
}

\section{Ibrahim Abdulai Sawaneh a, *}

a School of Management, Wuhan University of Technology, Wuhan, PR. China.

*Corresponding author email: ciddiisawaneh@yahoo.com

DOI: https://doi.org/10.34256/ajir20232

Received: 10-07-2020

Accepted: 30-09-2020

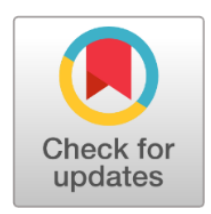

\begin{abstract}
The use of social media in a public emergency is dated back to the terrorist attacks (2001) in the United States. Since then, it is has been used to effectively manage critical happenings in public emergency or disaster events and also for managing future public emergencies. Unfortunately, the underdeveloped countries are far behind in the race to enhance infrastructures that would mitigate or avert critical events from happening. The effects of social media are keyed to public emergencies as it allows the instant flow of communication to a broader population, helps government or organizations locate those affected by the disaster, and to help further those organizations to manage the available resources allocated to that public emergencies effectively. It can be exploiting the appropriate social media tools focusing on the use of ICT before, during, or after the emergency crisis.

Furthermore, the exponential increase in fake news of modern times is a concern for government and organizations handling the public emergency crisis. The politicization of national issues is another limitation, as they help to spread fake news and unfounded rumors to score political gain during a public emergency crisis. The research concludes that social media is a valuable tool to mitigate or avert public emergency if there are enhanced infrastructures backed with strong laws that would punish fake news/rumors perpetrators and future potentials of social media.
\end{abstract}

Keywords: Public Emergency, Fake News, Social Media.

\section{Introduction}

Social media is an evolving field that is growing exponentially globally. It allows smartphone users to instantaneously post an event on the Internet that can be seen by a wider population. The number of social media platforms of modern times is on the increase, such as Instagram, Facebook, WhatsApp, Twitter, LinkedIn, YouTube, Skype, SoftTalk, Wechat, TikTok, Pinterest, and Snapchat that connect the global communities. The advancement of social media platforms has resulted in faster transmission of messages (videos, voices, and texts) and the capability to curb or avert harm done to an organization in a crisis (Semple, 2009). People across the globe can reconnect over WhatsApp. Breaking news in another part of the world can be seen immediately by someone in Sierra Leone on 
Instagram, Facebook, and Twitter. Social media allows people to connect to the global network even when resources such as landlines and smartphones are not working. Social media can as well help to ruin a country's reputation or accelerate the spread of harmful rumors (Semple, 2009) or fake news.

The increasing complexity and interactions between humans and their environment render us more exposed than ever to unforeseen events; such as recently as, the Ebola (Kaner, Schaak , 2014), the mudslide (The World Bank, 2017) and now the Coronavirus Pandemic (2019-2020) reminding us again that we are far from being prepared for public emergencies, especially the developing countries. In these public emergencies, the damage to a nation or global community has been enormous in terms of death, injury, job loss, bankruptcy, and property loss. The lasting economic impact nationally and internationally is more difficult to estimate. The current coronavirus is threatening the global community for a significant economic recession since 1930, according to a BBC report. The effects of an unfolding public emergency crisis can weaken a country's ability to function efficiently, thereby seriously harming people, structures, assets, and reputation.

The introduction of several social media tools and platforms has transformed the landscape of public emergency crisis response significantly over the last decade with the potentials of a social event now becoming a reality. With freely available software tools such as online discussion platforms and news channels, both public and private organizations can now disseminate, acquire, and analyze information more professionally and accurately. Furthermore, social media tends to thwart a public emergency crisis from escalating out of control, and hence, cannot ignore its ability also to intensify an unfolding public crisis.
The spread of fake news during this public emergency Coronavirus pandemic has created much pandemonium among the populations in Sierra Leone. Fake news alleging that the government was vaccinating pupils for coronavirus had killed two pupils lead to the death of a woman through cardiac attack after hearing the fake news. Also, the government has been able to prepare for public disturbance by unpatriotic Sierra Leone residing in the diaspora, urging people to demonstrate their selfish interest. Furthermore, a group of students in South Korea designed a social media platform to help people do contact-tracing of people infected with the coronavirus and warm others of areas where the infected people have visited (BBC, 2020). This contact-tracing app could help stop the Coronavirus pandemic, and about $80 \%$ of smartphone users would need to use it, says experts advising the NHS in the United Kingdom (BBC, 2020). The US tech-giants Apple and Amazon are also designing a similar app to help monitor the spread of the Coronavirus pandemic.

Furthermore, the politicization of social media has significant effects on politics, social movements, and the transmission of information. Social media is a powerful tool of modern times used to disseminate an event as it happens and keep the global community abreast of pertinent issues that may involve their survival. Political parties, especially those in opposition, used the social media platforms to fabricate rumors and fake news, particularly in Africa, to gain political scorecards against the ruling governments. We have seen members of a political party, especially those residing abroad to spread fake news and unfounded rumors in the name of politics to create chaos during and after a public emergency; the Ebola saga (2014-2016), the mudslide episode (2017), and the present Coronavirus pandemic. People even forged the Ministry of Information and Communication's website and other international news channels to inflate the numbers of infected people just 
to create chaos and instability in Sierra Leone. The paper examines the effects of social media in public emergency response mechanisms in Sierra Leone. It describes some of the critical concerns for social media platforms to be used assiduously in and after the emergency response period. It pinpoints lessons and best standards that would enhance public emergency management competencies and proactiveness through the use of social media platforms.

\section{Related work}

The continuous increase in the use of social media applications by more than half of the global population has changed our behaviors and ways of perceiving news. The widely used social media platforms include (Top Social Media Sites, 2020): Instagram over 1 billion monthly users; Wechat, 1.1 billion monthly users; YouTube with more than 2 billion monthly users; WhatsApp about 2 billion active users; Facebook had approximately 2.5 billion monthly users; Twitter accounting for 300 million active users; TikTok more than 800 million monthly users; Pinterest approximately over 320 million monthly users; Snapchat over 300 million active users; LinkedIn accounting for 675 million active users; and Google + Statistics about 395 million monthly users (Social Media Statistics., 2020) globally.

Social media is an essential tool of our everyday lives, including public emergency response management. Immediately after the terrorist attack, citizens designed wikis to collect information about the missing people (Palen, \& Liu, 2007), and the FEMA and the Red Cross exploit the web-based technological innovations to update the public by providing status reports (Harrald, Egan, \& Jefferson, 2002 and Reuter, Kaufhold, 2017). Social Media used in public emergencies became a hot research topic in 2006, generally referred to as crisis informatics. (Hagar, 2007 and
Palen, Vieweg, Liu, \& Hughes, 2009) classified a public emergency response as an extended social platform where information shared between official and public channels. Today, a public emergency response system "is a multidisciplinary field merging computing innovations and social science engineering in public emergencies, its central principle involves the use of personal information and communication technologies to react to public emergencies to cope with the uncertainties"( Palen, Vieweg, Liu, \& Hughes, 2009). During the past four years, several studies try to address public emergencies using social media platforms by scholars globally such as (Hiltz, Diaz, \& Mark, 2011, Pipek, Liu, \& Kerne, 2014, and Reuter, Ludwig, Friberg, PratzlerWanczura, \& Gizikis, 2015), and conferences including the ISCRAM. Also, a statement by the WHO concerning the outbreak of the novel Coronavirus (Covid-19) in Geneva (International Health Regulations, 2020).

Palen and Liu predicted in 2007 that the role played by the public in public emergencies are becoming more noticeable, dynamic, and reaches a larger population than ever before (Palen, \& Liu, 2007). Several studies have focused on the physical use of social media during a specific emergency (Denef, Bayerl, \& Kaptein, 2013, Hughes, Denis, Palen, \& Anderson, 2014 and Reuter, Ludwig, Kaufhold, \& Pipek, 2015). These studies established explicit methods in which social media can respond to various public emergency crises. Although numerous studies on public emergencies and disaster situations have surfaced, yet still numerous challenges pose significant effects of social media on communities, societies, countries, and the globe.

However, the government of Sierra Leone is unable to effectively design stringent measures for social media platforms during and after a public crisis, as currently there are no cyber laws for the country. For instance, in the UK and the US, people have been arrested 
for breaking the Covid-19 emergency laws, unlike in Sierra Leone, the government is unable to do so as no existing laws exist regarding either information security, privacy, cyber law, and information act to punish perpetrators. Therefore, the research will principally focus on the effects of social media platforms in public emergency response mechanisms in Sierra Leone and provide recommendations to the government.

\subsection{Public Emergency Response Situation}

Social media is a new phenomenon that enables social interaction and communication using Internet-based platforms. According to (Wright, \& Hinson, 2009), social media is a user-generated content distributed using the Internet to share and facilitate conversation between users and is among the leading platforms used for social interaction nowadays. Therefore, it could be a vital tool for public emergencies, as a critical time limitation on how to evacuate the affected people, locate and deliver available resources, as well as to generate applicable information and distribute them to the general public promptly. Essential data are crucial to making informed decisions about where to focus the attention and where to distribute the limited resources. However, obtaining reliable, accurate, and timely data is always a challenge, especially in situations where disasters develop rapidly with little or no better infrastructure and reduced disaster management plan. It is challenging for both public and private organizations to map and collect data in the affected environments. During a public emergency such as a global health crisis, flooding, earthquake, drought, famine, or a pandemic, professional emergency workers to rapidly overcome, and essential emergency services may be quickly exhausted. In April 2020, Japan, the US, Italy, Spain, and Iran reported that their medical infrastructures were overwhelmed by the daily rise in the coronavirus infections.

In a report to the US Congress on Hurricane Katrina, Michael Chertoff, Secretary to Homeland Security, highlighted "the prominence having accurate, timely, and reliable information about the true picture." $\mathrm{He}$ further acknowledged that the response efforts during Katrina "were significantly hampered by a lack of information from the ground" (Chertoff, 2005). The other key challenge during emergencies is information sharing and communication to facilitate coordination. Information needs to be shared appropriately and quickly exchanged between those involved at the appropriate place and time. Public emergency personnel may have a unique emergency management system to communicate with each other on federal, national, regional, and local levels, and globally in a pandemic situation. Also, effective and enhance communication is essential for the public emergency professionals and people in the disaster environment to better plan for the evacuation process, and help those in the disaster environment to avoid risks in a selforganized manner. Furthermore, information updates are essential for emotional reasons among the affected people.

However, the existing communication channels used by the government are neither sufficient nor adequately exploited to respond to major disasters. For example, the lack of an adequate and effective communication platform to inform and guide the public is among the failures in the response and recovery efforts during Hurricane Katrina in 2006, and in the Santa Barbara fires of 20072009 the capacity of the official Web sites were often insufficient to meet the demand. In Sierra Leone, misinformation and fake news on Facebook and WhatsApp is a big challenge for the government in handling the current Coronavirus pandemic. Even though the government has already designed websites, https://www.mic.gov.sl, 
https://www.dhse.gov.sl,

https://www.mohs.gov.sl, and a Facebook page at https://www.facebook.com/mic.gov.sl to update the general public on events surrounding the pandemic, however, there are people especially the political parties are substantially engaged in misinformation and fake news spread.

\subsubsection{Social Media as a Tool in Public Emergency Response}

Social media has impacted our lives today significantly from news sourcing to the interaction with friends globally, and it is unavoidable and compelling. Since 2004, social media has been exponentially growing, and its popularity has not reached its peak yet. Nowadays, social media platforms are a significant source of news and information. Social media is a unique platform used to interact with friends and clients. They provide a platform for users to interact and communicate beyond geographical boundaries and as well offer numerous potentials for sharing user-generated content, including photos, voice notes, text messages, and videos. The exponential rise in social media platforms in terms of subscribers, target the relevant post toward the audience using the social media platform and achieve success, especially during a public emergency. Currently, there are 3.5 active social media users globally by Emarsys in 2019. Among the reasons for the exponential growth of social media is because of the increase in mobile users worldwide. Most social media applications are available on mobile apps stores or customized for mobile browsing; easy accessibility makes mobile users prefer social media sites while on the go.

Facebook: Approximately 2.5 billion active users globally. It is a popular social media platform used in most countries globally. On Facebook, people can connect with other people, organizations, and groups that share a common interest. Facebook offers disaster management organizations, such as
FEMA, having three Facebook pages (Steff, 2013), the ability to keep the public informed of emergencies before, during, and after they occur. The FEMA helps the public to differentiate between rumors and facts concerning the response on the Covid-19 pandemic. It clearly stated three things to do to stop the spread of rumors during the present Covid-19 pandemic: find trusted sources of information, share information from trusted sources, and inform people not to share unverified information.

Trusted sources on coronavirus may include the following; https://www.coronavirus.gov, https://www.who.int, https://www.mic.gov.sl for trusted information concerning the coronavirus pandemic.

Always check for the blue verified icon next to the account name when using the social media platform, which indicates that it is an official account.

Twitter: Twitter is a social media platform with approximately 300 million monthly users allowing its users to tweet short messages, and their audience can see those tweets. Users on Twitter are limited only to using 140 characters or less in these tweets. A hashtag, for instance, \#ISawaneh makes it easier to find the user ISawaneh in the search. People search for tweets on the coronavirus, or other disaster events using the hashtag \#Coronavirus. Twitter has become an efficient and accessible way to report on public emergencies. The FEMA has about 34 accounts on Twitter, which allows the agency to keep the public informed during an emergency (Steff, T., 2013).

YouTube: YouTube is a video-sharing public website with 2 billion users globally. It allows people to upload their videos and also view videos that other people have uploaded. In public emergency management, YouTube can provide the public with information on what to do before an emergency occur. It is second to Facebook in popularity and usage. It 
includes a video on how to pack a "go bag" or other information on how to plan for a public emergency. It is the future entertainment platform.

Skype: Skype allows its users to communicate over the Internet. During an emergency, It is preferable than the cellphone or landline, as these outdated approaches become congested when call volume increases drastically. Due to the Covid-19 pandemic, many businesses and organizations have been shut down or reduce their staff globally, leading to a surge in virtual calling and messaging tools. Examples include Microsoft's (NASDAQ: MSFT) Skype, with a tremendous increase in usage. It has about 100 million active users and daily users of 40 million, according to the company's blog post (March 2020).

WhatsApp: WhatsApp is a social media application developed for smartphones in 2009 and now owned by Facebook. It is a social media platform mostly popular in Africa. Most undeveloped nations like Sierra Leone used it to report during a public emergency, as seen in the Mudslide, Ebola era, and the coronavirus pandemic. Most of the misinformation and fake news channeled using this platform in Africa. Unfortunately, since most of its users are mobile phone users whose Sim cards are not registered, it becomes a challenge for public emergency management. It has about 2 billion active users globally and is the leading social media platform used in Sierra Leone (Ibrahim Abdulai Sawaneh, 2020).

Line: Designed in Japan following the devastating Tohoku Earthquake in 2011. It allows users to call or text each other over the Internet (Mari Saito, 2012). It makes Line a cheaper and more reliable alternative to cellphones and landlines. Just like Skype, Line can be used during a disaster if traditional forms of communication such as smartphones or landlines fail. The Line had 4.1 million users in Japan (2013) and an additional 96 million users in Asia, the Middle East, Africa, South America, and Europe (Taro Kaji, 2013).

\subsection{Benefits of Using Social Media}

There are several benefits of social media used for a public emergency scenario (Eric T. White, 2014), including:

Reliable and Effective Communication: The Internet has proven to be more reliable, especially during a public emergency event than traditional communicating platforms. When smartphones fail during disasters, social media can be a reliable alternative form of communication.

Targets a larger Audience: Information on social media can reach a larger audience than the traditional communication platforms. It can be achieved by "sharing" a link on Facebook or by "retweeting" it on Twitter information will spread across the Internet quickly.

\section{Allows for Direct Communication:}

Social Media offers a disaster management organization, such as FEMA, the ability to communicate directly with the public. It permits governments and disaster organizations to provide precise information to the public during a public crisis.

Public Participation: The public can be informed of relevant updates directly from those involved in a public emergency crisis through social media platforms.

Cross-Organizational Lines: Social media allows emergency personnel on the scene to communicate directly across the organizational lines when necessary (ChengMin Huang, Edward Chan, and Adam Hyder, 2010). It helps emergency personnel to respond to a public emergency adequately.

Delivered Instantaneously: It allows events to reach its audience instantaneously as it happens with live streaming as opposed to the traditional news outlets reporting it. 


\subsection{Challenges of Using Social Media}

Just like any other technology, it also has limitations or disadvantages as outlined below:

\section{Misinformation and Rumors:} Misinformation and rumors can spread quickly like a bush fire in the wilderness, creating confusion during a disaster situation.

Unrecognized Potential: Some governments have not yet realized the full potential of social media usage in disaster management. Governments and relief organizations would be restricting the tools for preventing public emergence if they failed to use their full potential.

Non-use of Internet/Social Media: Social media are not used by everyone, especially in developing countries. Therefore, governments and relief organizations should find alternate ways to communicate with these people during a public emergence.

\section{Discussions and Results}

The research uses survey results conducted between March and April 2020 involving 209 participants. According to (Ibrahim Abdulai Sawaneh, 2020), 97.6\% say yes when asked if they use the Internet, $0.5 \%$ say no, and $9 \%$ when asked if yes how often as indicated in table 1.

Table 1. No. of Internet Users

\begin{tabular}{|l|l|}
\hline Choice & No. of respondents \\
\hline Yes & 204 \\
\hline No & 1 \\
\hline If yes, how often & 4 \\
\hline
\end{tabular}

Source: Survey Results from surveyplanet.com (2020)

Table 2 below shows the frequencies of social media application usage in Sierra Leone.
Table 2. Frequencies of social media applications in Sierra Leone

\begin{tabular}{|l|l|l|}
\hline Choice & $\begin{array}{l}\text { No. of } \\
\text { respondents }\end{array}$ & \% \\
\hline Facebook & 141 & 29.5 \\
\hline WhatsApp & 206 & 43.1 \\
\hline Twitter & 38 & 7.9 \\
\hline WeChat & 29 & 6.1 \\
\hline $\begin{array}{l}\text { QQ } \\
\text { International }\end{array}$ & 4 & 0.8 \\
\hline LinkedIn & 32 & 6.7 \\
\hline Skype & 24 & 5 \\
\hline SoftTalk & 4 & 0.8 \\
\hline
\end{tabular}

Source: Survey Results from surveyplanet.com (2020)

According to table 2 above, the survey indicated that $43.1 \%$ uses WhatsApp, followed by $29.5 \%$ uses Facebook, $7.9 \%$ uses Twitter, 6.7\% LinkedIn, 6.1\% Wechat, 5\% Skype, and QQ International and SoftTalk $0.8 \%$ respectively. It shows that the majority of social media users in Sierra Leone are using WhatsApp that has fewer security features compared to Facebook in stemming out fake news or misinformation. Its main reason why misinformation is rampant in developing countries, especially Sierra Leone. Furthermore, the absence of stringent laws regarding privacy, cybersecurity, and information security adds more problems to how to punish those who spread fake news and rumors, especially during a public emergency in the country.

Table 3 below shows the authentic media outlet people rely on during a public emergency in Sierra Leone. Only a few selected media houses have chosen due to limited time.

Table 3. Authentic Media outlet used in Public Emergency in Sierra Leone

\begin{tabular}{|l|l|l|}
\hline $\begin{array}{l}\text { News } \\
\text { Channels }\end{array}$ & $\begin{array}{l}\text { No. of } \\
\text { respondents }\end{array}$ & $\begin{array}{l}\text { Percentages } \\
(\%)\end{array}$ \\
\hline
\end{tabular}




\begin{tabular}{|l|l|l|}
\hline $\begin{array}{l}\text { Africa Young } \\
\text { Voice (AYV) }\end{array}$ & 111 & 16 \\
\hline $\begin{array}{l}\text { Sierra Leone } \\
\text { Broadcasting } \\
\text { Service (SLBS) }\end{array}$ & 116 & 16.7 \\
\hline FM 98.1 & 72 & 10.4 \\
\hline BBC & 149 & 21.4 \\
\hline CNN & 75 & 10.8 \\
\hline CGTN & 33 & 4.7 \\
\hline VOA & 31 & 4.5 \\
\hline Newspapers & 33 & 4.7 \\
\hline $\begin{array}{l}\text { Social Media } \\
\text { Applications }\end{array}$ & 20 & 2.9 \\
\hline $\begin{array}{l}\text { Accredited } \\
\text { Journalist }\end{array}$ & 55 & 7.9 \\
\hline
\end{tabular}

Source: Survey Results from surveyplanet.com (2020)

Table 3 above shows the media outlet people viewed as official news channels during a disaster crisis in Sierra Leone. According to (Ibrahim Abdulai Sawaneh, 2020), 21.4\% of Sierra Leoneans trust the BBC as an official news channel for reporting public emergency crises internationally. CNN, about $10.8 \%$, VOA $4.5 \%, 4.7 \%$ for CGTN and Newspaper respectively, $7.9 \%$ for accredited journalists and social media only account for $2.9 \%$, suggesting that most people rely on the traditional news media for reliable and authentic information relating to public emergency crisis nationally and internationally.

Furthermore, the majority of people in Sierra Leone trust traditional media sites, especially as opposed to social media platforms, especially the older generation, but the youth of today prefer social media platforms to interact and communicate with each other. According to the survey, $96.2 \%$ of the respondents are aware of the risk posed by social media relating to fake news and misinformation during a public emergency.
Also, $87.1 \%$ of the respondents are aware of the existence of fake social media/fake websites/fake email accounts. Further, about 82.3\% also trust the government official websites/channels for accurate information during a public emergency in Sierra Leone, such as that of the Mudslide, Ebola crisis, and the Coronavirus pandemic.

The survey also indicates that about $98.6 \%$ of the respondents suggest that the Ministry of Information and Communication should continuously involve in sensitization and public lectures on the effects of fake news and misinformation on social media nationwide. The respondents (91.9\%) further suggest that the government should legislate strong laws regarding fake news and misinformation on social media and news channels, and defaulters penalized for spreading such rumors and misinformation. The Independent Media Commission (IMC) should also review its regulations to help minimize the spread of fake news and misinformation on print and electronic media such as TV stations and newspapers. Likewise, the Sierra Leone Association of Journalists (SLAJ) should conduct professional training for its members, especially the ethic in journalism. Some journalists lack ethics and bias to the state as their loyalty lies to their political parties and not the state. The National Telecommunication Commission (NATCOM) should make it mandatory for mobile networking operators in the country to register all Simcard subscribers and also stop selling Simcard from unauthorized agents. Currently, no laws are governing the information and communication technology, privacy act, information security, cybersecurity, and cybercrime in Sierra Leone. The survey indicated that $48.3 \%$ of respondents suggested that the government punishes fake news and misinformation vendors severely, $33.5 \%$ suggested public apology, and $18.2 \%$ opt for a minimal fine. 
Table 4 below shows the fake news/misinformation actors in Sierra Leone, according to the results of the survey (2020), where political parties are the master planner of fake news/misinformation.

Table 4. Fake news/Misinformation Actors in Sierra Leone

\begin{tabular}{|l|l|l|}
\hline News Channels & $\begin{array}{l}\text { No. of } \\
\text { respondents }\end{array}$ & $\mathbf{\%}$ \\
\hline Political parties & 148 & 37.3 \\
\hline Diaspora & 81 & 20.4 \\
\hline Cybercriminals & 71 & 17.9 \\
\hline The Government & 21 & 5.3 \\
\hline Others & 76 & 19.1 \\
\hline
\end{tabular}

Table 4 shows the actors of fake news/misinformation in Sierra Leone. The survey shows that about $37.3 \%$ of the respondents indicated that the political parties are a great source of misinformation, especially during a public crisis, including even national elections. The diaspora accounts for $20.4 \%$ of fake news/misinformation in Sierra Leone, especially where the majority of the citizens are illiterate. Others, which may include rumors, fake newspaper publications, political propaganda accounts for $19.1 \%$, a further $17.9 \%$ of the respondents believed that cybercriminals are responsible for fake news/misinformation during a public emergency in the country. Only 5.3\% indicated that the government also fueled misinformation to gain political favor among its citizens.

Also, $82.8 \%$ of the respondents suggested that citizens should treat public emergency devoid of national politics, while $10 \%$ were in favor, and $7.2 \%$ said somewhat. $98.6 \%$ of the respondents think that fake news/misinformation will endanger the country's image internationally? Therefore, the study indicated that fake news/misinformation would cause chaos during a public emergency that will lead to the loss of lives, properties, and economic stagnation.

\section{Conclusion}

The study shows that majority of the youths used social media to interact and communicate, which is inexpensive as compared to the traditional communication platforms. It means that if exploited effectively, Social Media benefits will be numerous compared to the conventional media. It is instrumental when used in a public emergency event, as it can target a broader audience.

The study further indicated that people above 50 years are not conversant with social media as the youths of today. They may feel uncomfortable using these new technological innovations and favor using traditional media platforms. Therefore, it is essential to employ both traditional media platforms and social media platforms to reach a wider population.

Also, misinformation and rumors easily spread quickly over social media, just like a bush fire in the dry season. It leads to chaotic situations during a public emergency crisis. Public emergency organizations (public and private) need to counter any rumors or misinformation with the correct information. The Ministry of Information and Communication website https://www.mic.gov.sl and Facebook https://www.facebook.com/mic.gov.sl

provides reliable information to the public during and after a disaster crisis.

The study further indicated that using social media requires some form of education. Some industrialized nations have a high literacy rate as compared to an undeveloped country like Sierra Leone, where the rate of illiteracy is higher than the literate ones. To make social media useful for a public emergency is to introduce basic ICT courses starting from elementary schools to 
universities, as suggested by $98.6 \%$ of the respondents. Therefore, failing to increase the literate rate in any country will affect the use of social media during a public crisis.

\subsection{Strengths and Limitations of social media in Sierra Leone}

Table 5 below shows the strengths and limitations of social media when used in a public emergency. Thought, it has limitations, yet still, it is an essential tool for public emergence response.

\section{Table 4. Strength and Limitations of Social Media in Sierra Leone}

\begin{tabular}{|l|l|}
\hline Strengths & Limitations \\
\hline $\begin{array}{l}\text { Reliable } \\
\text { communication }\end{array}$ & $\begin{array}{l}\text { Rumors/misinformation } \\
\text { spread rapidly }\end{array}$ \\
\hline $\begin{array}{l}\text { Targets a wider } \\
\text { audience }\end{array}$ & Unrecognized potential \\
\hline $\begin{array}{l}\text { Direct } \\
\text { communication }\end{array}$ & Requires Internet \\
\hline $\begin{array}{l}\text { Public } \\
\text { participation }\end{array}$ & Electricity is require \\
\hline $\begin{array}{l}\text { Cross- } \\
\text { organizational } \\
\text { lines }\end{array}$ & $\begin{array}{l}\text { Requires some form of } \\
\text { Literacy }\end{array}$ \\
\hline $\begin{array}{l}\text { Conveyed } \\
\text { immediately }\end{array}$ & $\begin{array}{l}\text { Privacy and security } \\
\text { concern }\end{array}$ \\
\hline \begin{tabular}{l} 
Less expensive \\
\hline Easy to use
\end{tabular} & Requires update regularly \\
\hline
\end{tabular}

Social media is an essential tool that could save many lives during a public emergency response situation. Social media allows public emergency organizations to target a wider population with speed even before it happens. Also, using solar panels in rural environments where electricity is a big challenge that has further spread the use of social media in rural settings as compared to the past. Unlike its limitations, if carefully and effectively employed in a public emergency response situation, it would help disaster management organizations to instantaneously communicate with the public and keep them informed through social media platforms. The ability to communicate with the public helps to support effective public emergency mechanisms and enhance the public confidence that they will help during a public emergence.

\section{Recommendations}

The author, as a result of this, suggests the following recommendations to enhance the use of social media platforms to mitigate the effects on the loss of lives and properties during a public emergency crisis in Sierra Leone:

1. The Ministry of Information and Communication should monitor the information on the different social media websites and applications to be able to quickly stop the spread of rumors and misinformation following a public emergency crisis;

2. NATCOM should encourage the mobile network operators to install base stations nationwide to help the locals to have access to the Internet;

3. The Ministry for Basic Education and that of the Higher and Technical Education should collaborate and introduce ICT courses from elementary schools to Technical Vocational Institutes to the Universities. It will help improve ICT literacy in the country;

4. Also, the government should enact laws relating to the information age such as privacy and information security act, the cybersecurity and cybercrime act, and other essential laws and remove the 1965 public order act in the Sierra 
leone Constitution that has failed to address the present information age and Big data era;

5. That the defaulters of fake news/misinformation be penalized, to set a precedent;

6. All stakeholders including the Independent Media Commission, The Sierra Leone Association of Journalists, NATCOM, the state security personnel, civil society organizations and the Ministry of Information and Communication should embark on massive public sensitization on the dangers of spreading fake news/misinformation especially during a public emergence response situation;

7. Regular workshops/training conducted for all state security personnel to aid them to track misinformation as quickly as possible during a disaster crisis;

8. Mobile network operators should carefully monitor the activities of social media users especially in a public emergency crisis and report fake news vendor to the appropriate authorities for further investigation;

9. The government should invest science and engineering research in the various universities to help them break new grounds in information technology;

\section{References}

Cheng-Min Huang, Edward Chan, and Adam Hyder (2010), BMC Medical Informatics and Decision Making article "Web 2.0 and Internet Social Networking: A New tool for Disaster Management? - Lessons from Taiwan.

Chertoff: Katrina scenario did not exist at https://www.cnn.com/2005/US/09/03/katrina.chertoff/

Denef, S., Bayerl, P. S., \& Kaptein, N. (2013), Social media and the police - Tweeting practices of British police forces during the August 2011 Riots, In Proceedings of the 31st international conference on human factors in computing systems (pp. 3471-3480).

Eric T. White (2014), The Application of Social Media in Disasters, How can Social Media Support an Effective Disaster Response? Page 16. 
Hagar, C. (2007), The information needs of farmers and the use of ICTs. In B. Nerlich, \& M. Doring (Eds.), From Mayhem to meaning: Assessing the social and cultural impact of the 2001 foot and mouth outbreak in the UK, Manchester, United Kingdom: Manchester University Press.

Harrald, J. R., Egan, D. M., \& Jefferson, T. (2002), Web-enabled disaster and crisis response: What have we learned from September 11. In Proceedings of the Bled eConference (pp. 69-83).

Hiltz, S. R., Diaz, P., \& Mark, G. (2011), Introduction: Social media and collaborative systems for crisis management. ACM Transactions on Computer-Human Interaction (ToCHI), 18(4), 1-6

Hughes, A. L., Denis, L. A. S., Palen, L., \& Anderson, K. M. (2014), Online public communications by police \& fire services during the 2012 Hurricane Sandy. Proceedings of the conference on human factors in Computing Systems (CHI) (pp. 1505-1514). Toronto, Canada: ACM.

Ibrahim Abdulai Sawaneh (2020): A survey on "The Effects of Social Media on Public Emergency Response Mechanisms in Sierra Leone" https://app.surveyplanet.com/results/5e7cdb1d039d7362fa9787f6

Kaner, Jolie, and Sarah Schaack, (2016). Understanding Ebola: the 2014 epidemic, Globalization and health, (12.1) 1-7.

Mari Saito (2012), Reuters article "Born from Japan disasters, Line app, sets sights on US, China."

Palen, L., \& Liu, S. B. (2007), Citizen communications in crisis: Anticipating a future of ICTsupported public participation. The conference on Human Factors in Computing Systems (CHI) (pp. 727- 736). San Jose, USA: ACM Press.

Palen, L., Vieweg, S., Liu, S. B., \& Hughes, A. L. (2009), Crisis in a networked world: Features of computer-mediated communication on April 16, 2007, Virginia Tech Event. Social Science Computer Review, 27(4), 467-480. https://doi.org/10.1177/0894439309332302.

Pipek, V., Liu, S. B., \& Kerne, A. (2014), Special issue: Crisis informatics and collaboration. Computer Supported Cooperative Work (CSCW), 23 (4-6), 339-345.

Reuter C, Kaufhold M-A. Fifteen years of social media in emergencies: A retrospective review and future directions for crisis Informatics. J Contingencies and Crisis Management. 2017;00:117.

Reuter, C., Ludwig, T., Friberg, T., Pratzler-Wanczura, S., \& Gizikis, A. (2015), Social media and emergency services? Interview study on current and potential use in 7 European countries. International Journal of Information Systems for Crisis Response and Management (IJISCRAM), 7(2).

Reuter, C., Ludwig, T., Kaufhold, M.-A., \& Pipek, V. (2015), XHELP: Design of a cross-platform socialmedia application to support volunteer moderators in disasters. In B. Begole, J. Kim, K. Inkpen \& W. Woo (Eds.), Proceedings of the conference on Human Factors in Computing Systems (CHI). Seoul, Korea: ACM Press

Semple, E. (2009), Update your crisis comms plan with social media, Strategic Communication Management, 13(5), 7.

Social Media Statistics 2020: Top Networks by the Numbers at https://dustinstout.com/socialmedia-statistics/\#google-plus-stats.

Statement on the second meeting of the International Health Regulations (2005) Emergency Committee regarding the outbreak of novel coronavirus (Covid-19) in Geneva (2020) at 
https://www.who.int/news-room/detail/30-01-2020-statement-on-the-second-meeting-ofthe-international-health-regulations-(2005)-emergency-committee-regarding-the-outbreakof-novel-coronavirus-(2019-ncov)

Steff, T (2013), National Defense Magazine article "Social Media Changing the Way FEMA Responds to Disaster."

Taro Kaji (2013), Covario article "Introducing LINE, an Emerging Social Network for Mobile in Japan."

The 7 Top Social Media Sites you need to care about in 2020: https://spark.adobe.com/make/learn/top-social-media-sites/.

The World Bank (2017), Sierra Leone (PDF). Rapid Damage and Loss Assessment of August 14, A Report on the Landslides and Floods in the Western Area, Sierra Leone in the International Bank for Reconstruction and Development / International Development Association.

Wright, D., \& Hinson, M. (2009), An Updated Look at the Impact of Social Media on Public Relations Practice. Public Relations Journal, 3(2), 27.

\section{Funding}

This study was not funded by any grant

Conflict of interest

The Author has no conflicts of interest to declare that they are relevant to the content of this article.

About The License

(C) The author 2020. The text of this article is open access and licensed under a Creative Commons Attribution 4.0 International License 